known to regulate neurite outgrowth and network proteins, this study may be useful in the development of pharmacological therapy for ADHD.

\title{
CONTROLLED STUDY OF ATOMOXETINE IN ADHD
}

Researchers at the Department of Psychiatry, University of Nebraska Medical Center, Omaha, and other centers in the US conducted an 8-week, double-blind, placebocontrolled study of atomoxetine for treatment of ADHD in 101 children 5- and 6-years of age and older. The dose was titrated to a maximum of $1.8 \mathrm{mg} / \mathrm{kg}$ per day (mean final dose $1.4 \mathrm{mg} / \mathrm{kg}$ ). Parent and teacher ADHD-IV Rating Scale scores were significantly decreased with atomoxetine $(\mathrm{P}=.009$ and .02 , respectively). Clinical Global ImpressionImprovement Scale-criteria indicating much or very much improved were met by $40 \%$ of children treated with atomoxetine compared with $22 \%$ of children on placebo (Not significant, $\mathrm{p}=0.1$ ). Side-effects significantly more common with atomoxetine than placebo were decreased appetite, gastrointestinal upset, and sedation. Laboratory tests including electrocardiograms and mean blood pressure and weight showed no clinically significant changes. Despite benefits, $62 \%$ of children in the atomoxetine group remained significantly impaired at the end of the study. Some children demonstrated a robust response to atomoxetine whereas in others, the response was more attenuated. (Kratochvil CJ, Vaughan BS, Stoner JA, et al. A double-blind, placebo-controlled study of atomoxetine in young children with ADHD. Pediatrics April 2011;127:e862-e868). (Respond: Christopher J Kratochvil MD, Nebraska Medical Center, Omaha, NE 68198. E-mail: ckratoch@unmc.edu).

COMMENT. Atomoxetine in children under 6 years of age is off-label. In this study, the efficacy and tolerability of atomoxetine for 5- and 6-year-old children is similar to that seen in older children. Even with the maximum FDA approved dose (1.4 $\mathrm{mg} / \mathrm{kg}$ per day), combined with psychoeducational intervention, only $40 \%$ of atomoxetine-treated subjects were "much" or "very much" improved at study end. The authors acknowledge that comorbid ODD may have influenced the ADHD ratings in the young age group, and further longer treatment studies should be performed.

\section{DEMVELINATING DISORDERS}

\section{RISK FACTORS FOR MULTIPLE SCLEROSIS IN CHILDREN}

Risk factors for multiple sclerosis in 302 children presenting with CNS demyelination to health-care facilities in Canada included HLA-DRB1*15 alleles, previous infection with Epstein-Barr virus, and low serum 25-hydroxyvitamin D. MRI brain lesions, and CSF oligoclonal bands are probable precursors of multiple sclerosis (MS). Children with a normal MRI are likely to have a monophasic illness. At follow-up, $63(21 \%)$ were diagnosed with MS after a median of 127 days. (Banwell B, Bar-Or A, Arnold DA, et al. Clinical, environmental, and genetic determinants of multiple sclerosis in children with acute demyelination. Lancet Neurol May 2011;10:436-445). (Response: Dr Banwell, Hospital for Sick Children, Toronto. E-mail: brenda.banwell@sickkids.ca). 